\title{
Trajetória e desafios do ensino de comunicação em Goiás
}

\author{
Yoãomar Carvalho de Brito Neto*
}

\section{Resumo}

Este artigo apresenta uma análise da trajetória e da importancia do ensino de comunicaçăo em Goiás. Trata-se de uma questão de cidadania, que se impõe a professores $\mathrm{c}$ a csiudanies.

Palavras-chave: ensino de comunicação; cidadania; modelo pedagógico, modelo de formação; UFG.

\section{Introdução}

A informação está no centro de uma nova concepção da cidadania. A cidadania, por sua vez, está no centro de uma perspectiva contemporânea de democracia. A democracia, como construção política do homem, se realiza através da celebração do contrato básico de direitos e deveres dos cidadãos, que só o regime de liberdade pode engendrar e garantir. Segundo Blandine Kriegel,

nenhuma sociedade começa por um contrato voluntarista celcbrado entre indivíduos. Ela principia pela história e se perpetua pela transmissão. O contrato, ou seja, o momento da perpetuação, só vem em segundo lugar, quando a cada geração se dá a possibilidade de decidir se a vida em comum tcm (mesmo) utilidadc. A não precede à cidadania, como o passado prreexiste ao presente ${ }^{1}$.

Assim, a informação não pode se resumir à sua dimensão midiática. Insistir nesta perspectiva é uma forma mistificadora de fugir ao debate necessário sobre um tema que interessa ao

* Jornalista, doutorando pela Université de Rennes II, Haute Bretagne, França e professor da Faculdade de Comunicação e Biblioteconomia da UFG.

Comun. inf., v.1, n. 1, p. 142-152, jan./jun. 1998 
cotidiano das pessoas. Umberto Eco, em recente reflexão ${ }^{2}$, fala de seus receios diante do exagerado otimismo dos que vêem na Internet, por exemplo, a última possibilidade da democracia direta. Seria concluir que um expressivo volume de informação pudesse significar, como que por mágica, uma melhor condição do exercício democrático. A informação, felizmente, é conhecimento humano, como bem insistia Paulo Freire: "conhecer é tarefa de sujeitos, não de objetos. E é como sujeito e somente enquanto sujeito, que o homem pode realmente conhecer", pois "o homem é um ser da praxis, da ação e da reflexão".

A informação no Brasil sempre foi privilégio de poucos, da mesma forma que a cidadania continua sendo o distante sonho da maioria. Não é de estranhar que a organização do seu ensino tenha historicamente provocado a contestação destes poucos. Estes poucos, no entanto, utilizam-se rotineiramente da própria imprensa para dizer que a informação/conhecimento é assunto (propriedade) deles e de mais ninguém, valendo-se igualmente deste expediente no meio acadêmico ou científico. Assim, a imprensa e a universidade, contrariamente ao postulado liberal, tornaram-se o espaço público privilegiado do interesse privado, em que pesem meritórias campanhas em torno da idéia da liberdade e da democracia. Estas, como nos revela a história, sempre tiveram um nítido caráter de excepcionalidade social e politicamente demarcada .

\section{Um pouco de história}

Em Goiás, ocorreu o mesmo o fenômeno. O presidente da Associação Goiana de Imprensa (AGI), Walter Menezes, nos falava há dias de um fato coincidentemente revelador . No início dos anos 60, ao lado do presidente do Sindicato dos Jornalistas Profissionais em Goiás, José Osório Naves, eles insistiam junto ao reitor Colemar Natal e Silva na idéia de criação de um curso de jornalismo na UFG. A reação era de desânimo e de incredulidade. "Pra que curso de jornalismo, se nem jornais a gente tem por aqui"?, perguntavam os críticos de plantão.

$\mathrm{Na}$ realidade, a história do ensino de comunicação (jornalismo) em Goiás tem uma longa trajetória de lutas, em forma de pressões as mais diversas. A preocupação com a formação do jornalista

Comun. inf., v.1, n. 1, p. 142-152, jan./jun. 1998 


\section{4}

profissional remonta à própria criação da AGI no dia 10 de setembro de 1934. Em várias oportunidades, seus dirigentes insistiam no sentido de possibilitar o ensino do jornalismo e, assim, melhorar o desempenho dos seus associados.

Essa pressão ganhou mais dinâmica e consistência com a criação do Sindicato dos Jornalistas Profissionais no Estado de Goiás, no dia 14 de abril de 1959. A criação da Universidade Federal de Goiás, neste mesmo ano, constitui-se no desaguadouro natural destas demandas em torno de uma unidade de ensino de jornalismo. O reitor Colemar Natal e Silva chegou mesmo a promover vários encontros $\mathrm{ccm}$ jornalistas, com vistas à criação de um curso de jornalismo na UFG. Estas tentativas não prosperaram porque, em abril de 1964, o golpe militar enterrou este e outros sonhos nossos.

O golpe não parou a luta. A AGI, presididida pelo jornalista Walter Menezes, e o Sindicato dos Jornalistas, presidido pelo jornalista José Osório Naves, continuaram insistindo na idéia, realizando gestões junto às autoridades e ampliando o leque de simpatias ao projeto de ensino de jornalismo. Desta vez, eles conseguiram o sinal verde do reitor Jerônimo Geraldo de Queiroz, que determinou a abertura de estudos para viabilizar a criação do curso de jornalismo na UFG. O caminho estava livre.

O curso de jornalismo foi criado pela Resolução $n^{\circ} 015 / 66$, de 30 de setembro de 1966 e ele nasceria agregado ao Instituto de Ciências Humanas e Letras (ICHL), mas funcionando em salas cedidas pela Faculdade de Educação. Ao primeiro vestibular, em 1968, se inscreveram 80 candidatos, que disputavam 30 vagas. No entanto, no começo daquele ano letivo, somente nove alunos estavam matriculados. Destes, apenas quatro conseguiram concluir o curso, quatro anos depois: Marly Brasil, Reynaldo Rocha, Luiz Otávio Soares e Braz Wilson Pompeo de Pina (in memoriam).

Em 1970, o curso se consolidava com a criação da unidade acadêmica própria, o Departamento de Comunicação Social, então chefiado pelo professor Modesto Gomes da Silva. Foi, no entanto, o professor Antônio Maia Leite (in memoriam) o grande responsável pela sua estruturação administrativa e acadêmica. Além dos trabalhos de organização administrativa, ele con-

Comun. inf., v.1, n. I, p. 142-152, jan./jun. 1998 
seguiu os primeiros concursos públicos para preencher as vagas do recém-criado corpo docente que contava, entre outros, com os professores Hélio Furtado do Amaral, José Carlos C. Rocha, Francisco Eduardo Ponte Pierre, Valquíria Braga dos Santos, Thomaz Roland Hoag e Taylor Oriente (in memoriam).

A partir de então, o departamento, já funcionando em espaço próprio no Campus II, experimentou diversas grados curriculares, à medida em que, de Brasília, partiam igualmente as mais diversas orientações sobre o funcionamento dos cursos de comunicação. Já nesta época, o professor Maia Leite pregava a necessidade de criação de uma faculdade de comunicação (se falava na idéia de um Instituto de Comunicação, nos moldes do ICHL), ao lado de todos os demais integrantes do departamento. Volta e meia, esta bandeira era levantada por um ou outro chefe do departamento. As tentativas, no entanto, esbarravam em obstáculos de toda ordem, tanto dentro do ICHL como em setores outros da UFG (câmaras, conselhos, reitoria etc.).

Não obstante as diversas estratégias de luta e de encaminhamento, a bandeira da autonomia do ensino de comunicação encontrava sempre mais obstáculos que apoio no próprio meio universitário. Obstáculos não somente de ordem burocrática, mas também frutos de concepção política de influentes setores da própria UFG, contrários ao fortalecimento e à consolidação desta nova área do conhecimento. Contribuíram historicamente para este quadro hostil alguns fatores de ordem interna. De um lado, experiências mal conduzidas no processo de ensino do então Departamento de Comunicação, aliadas, de outro, à falta de uma concepção mais ousada de ensino (distanciamento dos modismos típicos da área) e extensão (relação com a comunidade), e ainda à inexistência de uma política de pesquisa. Todo este quadro contribuía para o fortalecimento dos adversários do ensino na área de comunicação, sem produzir, internamente, uma coesão política capaz de levar adiante um projeto autonômico.

Outra grande batalha do Departamento de Comunicação foi travada, sem dúvida, em torno do projeto de aquisição de equipamentos para os seus laboratórios (fotografia, redação, radiojornalismo, telejornalismo). Os laboratórios eram exigências oficiais e condi-

Comun. inf., v.1, n. 1, p. 142-152, jan./jun. 1998 


\section{6}

ção sine qua non para o credenciamento do curso de jornalismo, mas nunca havia previsão orçamentária para viabilizar suas aquisições.

Além, é claro, da histórica má vontade de setores da burocracia da UFG, inpacazes de entender (e liberar) qualquer investimento num curso considerado sem prestígio acadêmico e sem a aura de cientificidade. Sem laboratórios, o curso de jornalismo não seria reconhecido pelo MEC. Estava difícil desatar o nó da burocracia universíária. No início dos anos 70 , algumas turmas formadas já estavam no mercado de trabalho, mas sem habilitação. Começavam, pois, as pressões de ex-alunos, do sindicato, da associação, da imprensa, de maneira geral, para que a UFG desatasse este nó e validasse, via reconhecimento do curso, os diplomas de jornalismo.

Afora o ingente trabalho dos quadros da própria UFG, o curso ganhou um bom aliado, na pessoa do deputado estadual Wander Arantes de Paiva, então aluno de jornalismo. Político articulado e de trânsito fácil em Brasília, ele juntou-se aos esforços do departamento, conseguindo sensibilizar o Ministro da Educação, que liberou as verbas necessárias aos laboratórios. O curso de jornalismo foi reconhecido no dia 5 de novembro de 1975. Neste mesmo ano nascia o curso de relações públicas, já num clima politicamente mais favorável . O curso já contava com professores especializados, o que possibilitou, mais rapidamente, sua estruturação administrativa e acadêmica. O curso de relações públicas obteve uma vitória mais rápida. Seu reconhecimento se deu no dia 2 de agosto de 1978.

Em 1981, nascia o curso de radialismo (rádio e TV). Este curso teve uma história de muitas lutas, tanto para garantir seu fucionamento adequado (professores da área, equipamentos, espaço físico para laboratórios etc.) como para garantir seu reconhecimento. Em função do início da crise que se abateu sobre as universidades, em meados dos anos 80, o curso de radialismo sofreu os percalços deste processo, assim como aqueles relacionados à sua própria natureza acadêmica. Debates e seminários tentaram, ao longo de seis anos, encontrar soluções para os seus mais diversos problemas, principalmente os relacionados ao uso de equipamentos

Comun. inf., v.1, n. 1, p. 142-152, jan./jun. 1998 
laboratoriais tanto do próprio departamento como na Rádio Universitária. O curso só foi reconhecido no dia 10 de novembro de 1987.

O curso de biblioteconomia, criado em 1980, foi incorporado ao departamento de comunicação, constituindo-se área distinta administrativa e academicamente. Mesmo assim, o curso teve que enfrentar quase os mesmos problemas para ganhar $\mathrm{I}$. conhecimento do MEC. Depois de pressões diversas, de alunos e professores, o curso foi reconhecido no dia 2 de julho de 1985. A mesma forma de luta garantiu que todos os cursos possuam, hoje, os equipamentos necessários ao seu bom desempenho.

No final de 1996, os conselhos superiores, depois de um demorado processo de análise e discussões, autorizou a criação da Faculdade de Comunicação e Biblioteconomia, dentro do quadro geral de mudanças estatutárias, que permitiu um enxugamento administrativo nas diversas instâncias da UFG. No dia 20 de agosto de 1997, o reitor Ary Monteiro do Espírito Santo instalava a nova faculdade. Ao mesmo tempo, um novo curso - de propaganda e publicidade - era autorizado, começando a funcionar no início do ano letivo de 1997 . Brevemente, já estará funcionando seu laboratório, cujas providências rotineiras para aquisição já foram adotadas. No entanto, estão sendo projetadas as mesmas dificuldades para contratar os professores e instalar laboratórios necessários ao seu adequado funcionamento.

Neste meio tempo, a nova faculdade deve promover, dentro de um curto espaço de tempo, a discussão sobre a idéia de fusão ou não do curso de radialismo ao de jornalismo, porque não mais se justifica a manutenção de estruturas de ensino praticamente iguais. Há até mesmo uma proposta mais ousada, que apresentamos, de extinção do curso de radialismo, num primeiro momento, oferecendo-se especializações correspondentes ao final do curso de jornalismo. Assim, o curso de jornalismo se fortalece e a faculdade pode racionalizar o uso dos seus laboratório, permitindo melhor aproveitamento do seu quadro docente nas atividades de ensino, pesquisa e extensão. E permitirá, de outro lado, visualizar uma relação de competência com a sociedade goiana, formando profissionais capazes de fazer da

Comun. inf., v.1, n. I, p. 142-152, jan./jun. 1998 


\section{8}

informação um instrumento do exercício da cidadania e não do fortalecimento das corporações classistas.

Num segundo momento, a partir dos resultados da primeira experiência acima mencionada, repensar-se-ia toda a estrutura dos cursos da nova faculdade, não somente para as adequações de rumo ou exigidas pela legislação, para garantir uma segura sintonia com as necessidades da sociedade, tanto oferecendo profissionais bem formados (competentes, éticos, comprometidos com o ideal democrático) quanto elementos de crítica e compreensão dos fenômenos da informação e da comunicação, em tempos de globalização.

Isto não se dará sem motivo. Dentro dos novos planos da faculdade, afora a garantia de boas condições de funcionamento de todos os seus laboratórios e do trabalho docente, está em gestação o projeto de criação de um curso de mestrado em comunicação, que consolidará a nova unidade da UFG como referência na área da investigação científica (pesquisa) na região Centro-Oeste. Isto consolida os esforços realizados nos últimos dez anos, no sentido de qualificar adequadamente seus professores, permitindo que eles realizem cursos de mestrado e doutorado no Brasil e no exterior .

\section{Os novos desafios}

A instalação da nova faculdade da UFG é ponto de partida para outra caminhada não menos difícil. Encontrada a autonomia político-administrativa, a nova unidade tem desafios extraordinários pela frente. É exatamente onde mais pecou até aqui falta de maior clareza do projeto de ensino e inexistência de uma política de extensão e de pesquisa - que a nova faculdade deve consolidar sua autonomia. Isto pode iniciar-se tanto pelo empenho em qualificar adequadamente seu corpo técnico (suporte do ensino e da administração) como pela obrigatoriedade de dar ao quadro docente as condições de correto desempenho de suas tarefas (suporte do ensino e da pesquisa).

A nova faculdade - não custar recordar - 6 herdeira de um tradição de quase 30 anos de ensino (público) de comunicação em Goiás. Fruto da pressão exercida pelas corporações sociais

Comun. inf., v.1, n. 1, p. 142-152, jan./jun. 1998 
(entidades classistas e culturais), ela herdou igualmente toda a rica e tumultuada experiência de organização dos cursos de comunicação no Brasil durante os anos 70-80. As unidades de ensino de comunicação repercutiam, assim, as mudanças que a sociedade brasileira patrocinava, ao sair de uma ditadura para a experiência do exercício democrático. Sociedade e universidade são peças de uma mesma engrenagem social . A sociedade só reconhece as profissões que têm a chancela da universidade. Como lembra o professor José Marques de Melo, "neste sentido, a universidade se estrutura por pressão externa e seria de se esperar que ela mantivesse, nos períodos seguintes, essa articulação com este contingente do sistema produtivo".

No colóquio sobre os desafios do ensino de comunicação, realizado em 1991, em São Paulo, estabeleceu-se que

tal como o médico, o engenheiro, etc., o comunicador tem que ter consciĉncia da sua responsabilidade perante a sociedade e da ética no desempenho de sua profissão. Portanto, na formação desse profissional devem constar duas linhas básicas: a do instrumental tecnológico, manipulado competentemente, e a do contcúdo cultural, que o torne apto a situar-se na sociedade e a vislumbrar caminhos possiveis.

Insistiu-se também em que

(...) o ponto essencial é o estabelecimento de prioridades, identificando os campos do conhecimento que permitem melhor compreender o comportamento do homem na sua complexidade individual e colctiva. Empresários e ex-alunos devem colaborar no estudo destas prioridades".

Aos primeiros desafios da nova faculdade da UFG (clareza do projeto de ensino e extensão e implantação urgente da pesquisa), que instalam as pré-condições do processo de sua consolidação, não é necessário inventar muito, situando-se no marco das duas linhas antes referidas. $\mathrm{O}$ que lhe cabe, evidentemente, é ousar nas tarefas do dia-a-dia e não perder de vista as exigências da sociedade. A idéia básica é exatamente a de ter a sociedade como referência, desprezando-se os atrativos e os encantos de sereia proporcionados pelo chamado "mercado".

Comun. inf., v.1, n. 1, p. 142-152, jan./jun. 1998 


\section{0}

Todos sabemos que a democracia é uma construção política do homem. Nesta direção - olhando atentamente para a sociedade -, uma unidade de ensino público em comunicação e informação tanto pode (quanto deve) contribuir para fazer da cidadania uma bandeira de luta cotidiana, posto que se trata de uma construção política alicerçada na informação/conhecimento etc.

Tendo o ensino da informação e da comunicação como instrumento gerador de sua existência, a nova unidade acadêmica precisará alargar os espaços de sua atuação, pois, se é correto que a cidadania está no centro de uma concepção contemporânea de democracia, é fundamental entender a real dimensão do espaço de sua realização, porquanto perpassa a reflexão sobre o papel desempenhado pela informação, seja no plano dos meios formais de comunicação, seja no universo da comunicação interpessoal. É neste universo que se dá a passagem do indivíduo à condição de cidadão. Este processo se dá pela aquisição de informação, seja na forma de conhecimento produzido pela sistema familiar e educacional, seja na sua forma midiática.

O filósofo belga André Berten sugere que, neste caso, a necessidade de trabalharmos os vários níveis de competência dos atores, "ingrediente necessário de socialização dos indivíduos". É necessário, pois, entender os variados níveis de competência do indivíduo, quando desafiado ao exercício da política. Assim, é desafiadora e urgente a possibilidade de determinar os fatores responsáveis pela constituição dos níveis desta competência individual. Neste contexto, a educação e a informação jogam um papel decisivo, porque podem fazer do indivíduo um cidadão, o homem-sujeito, autor e ator de sua própria história.

Hoje, estamos diante de novos desafios num mundo de jornais, de rádio e tevê, de agências de publicidade, de um sólido parque gráfico, tudo interconectado pela informática que, sem que nos demos conta, estão agendando nosso cotidiano, definindo opções políticas ou mesmo determinando preferências.

Ainda assim nos perguntamos sobre a validade do ensino de comunicação e da informação, num mundo globalizado exatamente pela informação. E ainda se pergunta para que serve uma faculdade de comunicação e informação, na estrutura do ensino superior

Comun. inf., v.1, n. 1, p. 142-152, jan.jun. 1998 
brasileiro! (não confundir formação com obrigatoriedade de diploma para o exercício da profissão!). Parece evidente, em todo caso, que a experiência de 30 anos de ensino de jornalismo na UFG (1968-1998) e uma (coincidente!) reestruturação qualitativa do sistema de comunicação em Goiás (jornal, rádio e TV) são sináis mais do que claros de sua importância. Basta observar os setores (alguns jornais e emissoras de rádio) que ainda insistem em desprezar, em seus quadros, profissionais formados em comunicação, para verificarmos o acerto da instituição deste tipo de ensino em Goiás. Os críticos insistem em criticar a universidade por ser teórica, em prejuízo da prática. Quando não existen, por exemplos, cursos, alguns setores levantam bandeiras, exigindo que o poder público os ofereça. Quando são oferecidos, em geral, os mesmos setores viram a cara.

$\mathrm{O}$ que falta à universidade é precisamente uma boa teoria, que nos livraria a todos destes e de outros equívocos. Na Europa, por exemplo, profissionais de imprensa ou especialistas em comunicação e informação têm sua formação acadêmica centrada exatamente num bom escopo teórico e não é sem razão que no velho continente (França, Inglaterra, Espanha, principalmente) se encontram ainda as melhores referências em matéria de imprensa (jornais, rádio e tevê) e de pesquisa dos fenômenos da informação e da comunicação (universidades e centros de pesquisa).

Para que serve, então, uma Faculdade de Comunicação e da Informação?

Eu entendo que ela serve a este processo de construção da cidadania. É uma tarefa claramente política. A educação/informação nos encaminha para a descoberta dos direitos e dos deveres. A educação/informação nos conduz à consciência política, criando a idéia de cidadania. Esta consciência é que faz o homem cidadão, autor e ator de sua história. Este desafio será melhor enfrentado, quanto maior for a clareza de propósitos da nova faculdade na condução dos seus objetivos fundamentais (ensino, pesquisa, extensão). Pois, se é fundamental formar profissionais com adequado preparo técnico, melhor mesmo é dotá-los de uma inquebrantável formação ética que, segundo Edgar Morin, "deve mobilizar a inteligência para enfrentar a complexidade da vida, do mundo e da própria ética", 


\section{Abstract}

This article shows an analysis of trajectory and of importance of communication teaching in Goiás. This question of citizenship is absolutely in order to enable teachers and students.

Key words: communication teaching; citizenship; pedagogical model; formation model; UFG.

\section{Notas}

1. KRIEGEL, Blandine. Quelle démocratie, quelle citoyenneté. Paris: Éd. L'Atelier, Éd. Ouvriéres, 1995. p. 50.

2. ECO, Umberto. Votação no ciberespaço. O Estado de São Paulo, 6 jul. 1997. p. 2.

3. FREIRE, Paulo. Extensão ou comunicação?. 2.ed. Rio de Janeiro: Paz e Terra, 1985. p. 28.

4. MELO, José Marques de. O ensino de comunicação e as transformações da universidade. In: UNIVERSIDADE DE SÃO PAULO. Escola de Comunicações e Artes. O ensino de comunicação e os desafios da modernidade. São Paulo : ECA-USP, 1991. p. 15. (Simpósios em Comunicações e Artes, n. 8).

5. UNIVERSIDADE DE SÃO PAULO. Escola de Comunicações e Artes. O ensino de comunicação e os desafios da modernidade. São Paulo: ECA-USP, 1991. p. 2-3. (Documento do Colóquio Nacional promovido pela Escola de Comunicações e Artes, São Paulo, 3-5 ago. 1991).

6. BERTEN, André. D'une sociologie de la justice à une sociologie du droit. Recherches Sociologiques. Louvain-La-Neuve, v. 24, n. 1/2, 1993.

7. MORIN, Edgar. A angústia do pregador contra a crueldade (entrevista). Jornal do Brasil, 06 jul. 1997, cad. B, p. 6 .

Comun. inf., v.1, n. 1, p. 142-152, jan./jun. 1998 